\title{
O uso de linguagens documentárias por indexadores em contexto de bibliotecas universitárias: uma abordagem sociocognitiva com protocolo verbal
}

The use of documentary languages by indexers in a university library context: a sociocognitive approach with a verbal protocol

\section{Mariângela Spotti Lopes FUJITA (1) e Franciele Marques Redigolo (2)}

(1) Universidade Estadual Paulista Júlio de Mesquita Filho - UNESP, Programa de Pós-Graduação em Ciência de Informação, Av. Hygino Muzzi Filho, 737, Campus Universitário, CEP. 17525900 - Marília, SP, Brasil, Caixa-Postal: 421, fujita@marilia.unesp.br; (2) franbiblio@gmail.com

\begin{abstract}
Resumen
Se investiga, con un abordaje socio-cognitivo, el uso de lenguajes documentarios por indizadores profesionales para la representación documentaria en la indexación, búsqueda y recuperación, en las bibliotecas universitarias de la Universidad Estadual Paulista "Júlio de Mesquita Filho" de Pedagogía, Ingeniería Civil y Odontología. Se aplicaron tres protocolos verbales individuales a los bibliotecarios mientras realizaban la tarea de indexación durante la catalogación de libros. Al carecer de un lenguaje documental, los profesionales prácticamente no pudieron hacer una traducción de los términos identificados en el documento. Por el contrario, los términos son extraídos de las fichas catalográficas de los documentos, sin adaptarlos a la nueva institución.
\end{abstract}

Palabras clave: Lenguaje documentario. Análisis de asunto. Indización. Bibliotecas universitarias. Universidade Estadual Paulista.

\section{Introdução}

A indexação é vista como um processo intelectual que depende da cognição profissional. $O$ domínio do contexto físico, psicológico e sociocognitivo é necessário para que o indexador realize a identificação e seleção de conceitos na concepção orientada para conteúdo e para a demanda. O processo de indexação consiste em analisar, encontrar, descrever e representar o conteúdo dos documentos, utilizando-se de termos significativos que tornam possível a recuperação do documento pelo usuário final. $O$ indexador tem como objetivo encontrar conceitos durante a análise de assunto para representar o conteúdo dos documentos. E, posteriormente, para fins de busca do usuário, os documentos precisam estar representados de acordo com a realidade em que estão inseridos.

\begin{abstract}
A socio-cognitive-based research is presented on the use of indexing languages in indexing and retrieval by the professional cataloguers of the libraries of Education, Civil Engineering and Dentistry of the State University Paulista "Júlio of Mesquita Filho" (UNESP). Three verbal protocols were applied individually to the indexers while doing their work. They rarely use an indexing language and therefore they could not translate the terms identified in the document. Instead, they apply the subject headings coming with the derived cataloguing records, without adapting them to the new institution.
\end{abstract}

Keywords: Indexing languages. Subject analysis. Indexing. University libraries. Universidade Estadual Paulista.

Um fator determinante para a realização do trabalho do indexador é o contexto em que está inserido. O contexto é uma variável importante, porque estabelece e delimita o desempenho do indexador dentro da unidade. Sendo assim, esses catalogadores precisam exercer as suas atividades de acordo com o interesse dos usuários que utilizam o sistema de busca da biblioteca.

A indexação, processo que provê acesso ao documento, pode gerar ruídos e silêncios durante a busca se não for realizada na perspectiva dos usuários e do seu domínio de assunto. Para Chaumier (1971, p. 20) o ruído define-se como sendo "a percentagem de documentos que não respondem à questão levantada e selecionados quando da interrogação, em consequência, essencialmente, de combinações acidentais de característica ou de confusões, no sentido quan- 
to aos termos de caracterização." Oposta à a essa noção de ruído, está a noção de silêncio, que é "a percentagem de documentos pertinentes que respondem a uma questão existente na memória e não selecionados quando da interrogação" (Chaumier, 1971, p. 20).

Os problemas apontados poderão ser observados através do usuário quando tem dificuldades de recuperação das informações indexadas nos catálogos, bem como da observação do conhecimento prévio do catalogador de assuntos sobre linguagem documentária que utiliza durante a leitura documentária para catalogação levando em conta o contexto em que os documentos estão inseridos.

Desta forma o problema desta pesquisa centrou-se na dificuldade dos catalogadores na representação documentária em áreas específicas de Bibliotecas da Universidade Estadual Paulista "Júlio de Mesquita Filho" - Unesp.

A investigação teve como foco o contexto do leitor profissional, na perspectiva do conhecimento prévio do indexador construído mediante as suas interações com o ambiente de trabalho, mais especificamente em áreas específicas de bibliotecas universitárias.

Tendo em vista a concretização desta proposta, o trabalho desenvolveu estudo do contexto com abordagem sociocognitiva da análise de assunto para tratamento de conteúdos documentários em Bibliotecas Universitárias e a investigação do conhecimento prévio do catalogador de assuntos sobre linguagem documentária que utiliza durante a leitura documentária para catalogação de assuntos de livros com uso da técnica introspectiva de coleta de dados do Protocolo Verbal Individual em Bibliotecas da Universidade Estadual Paulista "Júlio de Mesquita Filho" Unesp.

\section{Tratamento temático da informação em bibliotecas universitárias}

As Bibliotecas Universitárias são organizações voltadas para o apoio ao ensino, à pesquisa e à extensão, e são essas atividades que dão suporte ao desenvolvimento das universidades. Elas desenvolvem ações, produtos e serviços voltados a sua clientela de tal maneira que se atinjam os objetivos e metas traçadas por um determinado período. São sistemas de informação que produzem bases de dados cujas formas de representação documentária estão organizadas em metadados com possibilidade de acesso múltiplo. Portanto, são instrumentos plurifuncionais porque dão acesso, confirmam dados e possibilitam avaliação (Fujita, 2007).
Por serem organizações inseridas em um meio dinâmico, de mudanças contínuas, as bibliotecas universitárias têm acompanhado, ao longo dos anos, as transformações ocorridas na sociedade como um todo e dessa maneira elas têm buscado uma melhoria na apresentação de seus produtos e serviços de tal modo que sua clientela interna e externa fique satisfeita com os resultados obtidos. Sendo assim, sente-se a necessidade de aprimoramentos e melhores especificações no desenvolvimento das atividades dentro desses centros informacionais.

A condição do atual crescimento da produção científica, aliado a interdisciplinaridade entre as áreas do conhecimento, faz com que o trabalho do organizador das informações, fique cada vez mais complexo, tornando-se um desafio para este profissional. Juntamente com este crescimento documentário, aumenta a necessidade de se tratar tematicamente as informações considerando suas formas específicas, assim como a comunidade usuária e o contexto de especialização do acervo.

A necessidade de tratar tematicamente a informação de uma forma mais específica é devido às especializações dos acervos, criando novas formas de representação para uma recuperação mais ágil (Novellino, 1996). A atividade de indexação é realizada com mais intensidade desde o aumento das publicações periódicas, e também do aumento da literatura técnico-científica, surgindo, então, a necessidade de criação de mecanismos de controle bibliográficos em centros de documentação especializados.

Dentro da perspectiva evolutiva do tratamento da informação, está vinculada a indexação como operação do tratamento temático que comporta a análise, síntese e representação (Silva; Fujita, 2004).

Dentro desse bojo de evolução de técnicas de tratamento da informação, está ligada a análise documentária como extensão do tratamento temático que comporta a geração de resumos e a indexação (Fujita, 2003, p. 61).

Em um contexto de Bibliotecas, o tratamento temático da informação é realizado pela classificação e catalogação de assuntos e assim, podemos articular a indexação e a catalogação de assuntos, como sendo a mesma atividade, pois, o resultado de seus processos resultará na análise de assunto dos documentos.

Na visão de Chaumier (1980) citado por (Fujita, 2004, p. 137), a indexação

é a parte mais importante da análise documentária.

É ela quem condiciona o valor de um sistema documentário. Uma indexação insuficiente representa 
$90 \%$ das causas essenciais para aparição de ruídos ou de silêncios.

Se a representação for mal feita, não adiantará desenvolver linguagens e nem habilitar pessoal para uso desta linguagem. Ainda sobre a eficácia de uma unidade informacional, Langridge (1989), apud Dias (2004, p. 147), diz que:

nenhum sistema de recuperação de informação pode ser melhor que a análise de assunto que nele é realizada. Qualquer conceito que escape na análise, não será representado na linguagem do sistema.

A qualidade dos produtos (catálogos, índices, etc.), vai depender em grande parte da competência com que o trabalho de análise de assunto for realizado.

A leitura profissional, portanto, é voltada para a análise de um documento com a finalidade de realizar a indexação para representação do conteúdo por meio de termos que serão posteriormente recuperados por um usuário no sistema de informação. Na leitura para fins documentários e tratamento da informação, ou leitura técnica, não é necessário e nem aconselhável que se faça uma leitura linear, letra por letra, palavra por palavra. Neste tipo de leitura o leitor avança no texto à medida que consegue predizer o que vem a seguir (Fujita; Nardi; Santos, 1998).

A importância da análise de assunto destaca-se nas pesquisas que procuram determinar os tipos de busca em sistemas de recuperação da informação mais solicitados pelos usuários. Alguns estudos (Taylor, 1995), (Kern-semirenko, 1983), (Larson, 1991) e (Peters, 1989) apud Dias; Naves; Moura, 2001) demonstram resultados significativos em relação à busca por assunto, e que esse tipo é o mais solicitado pelos usuários. Entretanto, consideram que, apesar de ser o mais solicitado, não preenche de forma satisfatória as funções cumpridas pelos sistemas que adotam linguagens controladas.

Tendo a perspectiva do contexto envolvido nas decisões dos indexadores e o uso de linguagens documentárias, Pinto (2001) afirma que a representação temática do conhecimento registrado, tendo em vista a indexação de documentos, pode ser realizada tomando-se por base os conceitos representativos dos documentos ou palavras-chave. Neste caso também podem ser extraídos do documento mesmo ou ainda atribuídos a partir de outras fontes como as Linguagens Documentárias.

\section{Linguagens documentárias}

A Ciência da Informação ao construir as linguagens documentárias tem como objetivo assegu- rar a organização e a transferência da informação armazenada. A informação necessita de uma organização que faça sentido, tanto para o sistema quanto para seus usuários. As linguagens documentárias são linguagens construídas para indexação, armazenamento e recuperação da informação e correspondem a sistemas de símbolos, destinadas a traduzir os conceitos dos documentos (Cintra, 2002).

Em uma unidade informacional é muito importante que exista uma circulação dos conteúdos que se encontram disponíveis através de instrumentos capazes de compatibilizar a linguagem adotada no sistema com a linguagem de busca pelo usuário final de uma área especifica (Fujita; Cervantes, 2005).

A atuação de uma linguagem documentária na recuperação da informação é um fator essencial na obtenção de informações satisfatórias para o usuário, possibilitando a realização de investigações que contribuam para a pesquisa, melhorando e agilizando o processo da busca informacional. A linguagem documentária pode ser vista como um instrumento de mediação entre sistemas e conjuntos informacionais e os usuários. Exerce a função de ponte entre ao menos duas linguagens, a linguagem do sistema e a do usuário. Pode ser vista como um sistema significante, um meio organizado em torno de uma área temática (Lara, 2004).

O papel da linguagem documentária é de dar forma ao conteúdo dos documentos. Lara (2004) argumenta que para a linguagem documentária desempenhar um papel de comunicadora, deve apresentar uma série de qualidades, entre essas se podem destacar a de funcionar como código inteligível e fonte para interpretação do sentido, bem como caracterizar-se como metalinguagem e incorporar o usuário como integrante do processo.

Santos (1997) elucida que, através da linguagem, acontece uma comunicação entre os seres humanos, uma relação de criação e troca de mensagens, enquanto que a língua é por sua vez, qualquer sistema de signos. A Linguagem Documentária coloca ao alcance do usuário a informação desejada de uma forma simbólica, em uma organização de termos e regras próprias do sistema de recuperação da informação.

Referente à atividade de indexação, Naves (2001) mostra alguns fatores determinantes, com relação à influência que o indexador sofre durante a análise de assunto. São aspectos como a subjetividade (diferentes idéias da mesma informação, ou idéias que não se apresentam muito claras), o conhecimento prévio (que é o conhecimento armazenado na memória 
de cada indivíduo) e a formação e experiência do catalogador.

As linguagens documentárias são auxiliares na atividade de representação e recuperação de informações, e atuam nos sistemas de informação orientando o profissional indexador sobre quais os melhores termos para representação do assunto de um documento e orientando os pesquisadores na elaboração das estratégias de busca de informações no sistema.

\section{Contexto sociocognitivo do indexador}

A perspectiva sociocognitiva em indexação é necessária porque o objetivo da condensação e da representação documentária é a recuperação da informação. É imprescindível que o indexador junte o seu conhecimento prévio (conhecimento acumulado durante toda a vida), a conhecimentos específicos, para que a análise de assunto seja realizada com bons resultados.

A mente humana é um processador de informação que recebe, armazena, recupera, transforma e que também tem a capacidade de transmitir a informação, e que tal informação, bem como os outros processos correspondentes podem ser estudados como padrões e manipulações de padrões (Koch, 2002).

A concepção cognitiva nasceu da investigação do comportamento mental humano. No cognitivismo a concepção de representação na mente humana é inata e a mente tem a finalidade de processamento de informações. A cognição é compreendida como os processos mentais inconscientes de uma pessoa, enquanto a metacognição refere-se ao gerenciamento consciente sobre um fenômeno cognitivo do indivíduo.

As estratégias de pensamento são um conjunto de processos que o sujeito realiza com vistas à consecução de um objetivo que é o de assimilar a nova informação (Bernard, 1995). As estratégias de leitura são percebidas quando há uma ruptura na compreensão, então, o leitor desacelera a leitura e torna-se cognitivo (Cavalcanti, 1989). Para Fujita e Cervantes (2005), a cognição é uma ação e a aprendizagem é uma negociação entre sistemas e meio, por isso, se não ocorrer a interação, não haverá a cognição.

O contexto faz a intermediação entre a situação real dentro da unidade de informação e a representação dos itens indexados - vistos como sistema lingüístico. O contexto é uma variável importante, porque estabelece e delimita o desempenho do indexador dentro da unidade, de modo que esses catalogadores precisam exercer as suas atividades de acordo com o interes- se dos usuários que utilizam o sistema de busca da biblioteca.

O contexto visto como uma variável pode agregar valores em determinados termos, podendo este assumir novos significados, apenas mudando o seu foco de análise. Segundo Koch (2002), o contexto sociocognitivo é compreendido como a interação entre contextos cognitivos, de modo que os conhecimentos, de diversas origens, sejam parcialmente compartilhados. $\mathrm{O}$ contexto sociocognitivo, conforme Koch (2002) inclui todos os tipos de conhecimentos que estão armazenados na memória do que se denomina de "actantes sociais" que necessitam serem utilizados durante um intercâmbio verbal. Esses actantes são: conhecimento lingüístico, conhecimento enciclopédico, conhecimento da situação comunicativa e de suas regras, conhecimento superestrutural, conhecimento estilísti$\mathrm{co}$, conhecimento de outros textos (intertextualidade). O uso desses conhecimentos prévios durante $\mathrm{o}$ processamento textual se realizará mediante estratégias de diferentes tipos.

Analisando o contexto na sua abordagem sociocognitiva, podemos considerar que o contexto físico não interfere diretamente na linguagem. $O$ agente que pode ocasionar mudanças é o leitor, usuário daquele ambiente. Assim, o contexto que age como variável influente para interferir no modo de representação documentária em uma unidade é o conjunto de suposições trazidas para a interpretação de um enunciado (Koch, 2002).

O contexto sociocognitivo do indexador e do catalogador de assuntos inclui a política de tratamento da informação da biblioteca que inclui a linguagem documentária a ser utilizada na unidade informacional.

Um termo só assume um verdadeiro sentido, quando o contexto da situação é considerado e, deste modo, o indexador precisa ajustar as suas decisões conforme as necessidades que o meio exige (Koch, 2002).

Assim, o catalogador tem um respaldo maior para o desenvolvimento da análise de assunto do que somente a utilização de seu contexto individual para o desenvolvimento da indexação.

\section{Metodologia}

A pesquisa teve caráter exploratório e para suas finalidades, utilizaram-se os dados coletados pelo projeto "Política de tratamento da informação documentária da rede de bibliotecas da Unesp" (Fujita, 2006), coordenado pela Profa. $\mathrm{Dr}^{\mathrm{a}}$. Mariângela Spotti Lopes Fujita. Esse projeto propõe a elaboração de estudo diagnóstico 
do funcionamento e procedimentos do tratamento da informação documentária na Rede de Bibliotecas da Unesp mediante coleta de dados quali-quantitavos utilizando a técnica introspectiva de Protocolo Verbal nas modalidades individual e em grupo. O projeto, em questão, visa não somente à melhoria na apresentação de melhores produtos e serviços para a sua comunidade acadêmica, mas também apresenta o interesse em educar continuamente a sua equipe com o intuito de dar continuidade à formação dos seus catalogadores.

Para a análise do Protocolo Verbal Individual nesta pesquisa escolhemos a modalidade da Catalogação Original (CO) realizada pelos catalogadores de assunto em três bibliotecas da Universidade Estadual Paulista "Júlio de Mesquita Filho" - Unesp.

O Protocolo Verbal Individual consiste em analisar todo processo de verbalização do participante enquanto realiza sua atividade com o mínimo de interação com o pesquisador. Esta exteriorização é gravada e transcrita literalmente, produzindo protocolos verbais.

Para a análise dos Protocolos Verbais Individuais foram observados os procedimentos realizados pelo catalogador durante a atividade de catalogação de assunto com objetivo de observar o uso do conhecimento prévio da linguagem documentária durante a leitura documentária para catalogação de assuntos de livros. Os procedimentos observados foram divididos em três categorias de análise:

- -Associação com a linguagem documentária (Borba, 2003) será entendida como processo acoplado ao conhecimento prévio do profissional sobre a linguagem documentária do sistema;

- Validação pela linguagem documentária (Borba, 2003), será entendida quando o indexador mostrar que o termo foi identificado com base na linguagem documentária sem, contudo, ocorrer compreensão da atividade executada; e

- Dissociação ou não uso da linguagem documentária, quando o indexador recorre a outras fontes para definir o assunto do documento

As duas primeiras categorias foram extraídas do estudo de Borba (2003), cujo objetivo era observar o uso da linguagem documentária pelo profissional durante a indexação. O uso da linguagem documentária foi diferenciado entre associação e validação.
A terceira categoria foi criada, nesta pesquisa, durante a leitura detalhada dos protocolos verbais individuais quando se observou que os catalogadores referem-se a outras fontes de controle de vocabulário, além da linguagem documentária, para a identificação de termos na catalogação de assunto. Os catalogadores referiram-se, pelo conhecimento prévio, a fontes tais como: professores especialistas, bibliotecárias de referência, a base de dados de metadados do catálogo online, entre outros.

\section{Resultados}

A análise da tarefa dos três catalogadores foi observada pela leitura detalhada dos procedimentos destes catalogadores em relação à catalogação de assunto. Na sequência de procedimentos realizados pelos catalogadores notouse a inexistência de uma padronização. No quadro a seguir apresenta-se parte da seqüência dos procedimentos dos três catalogadores.

Categorias de análise dos resultados acompanhadas pelas verbalizações dos catalogadores:

Associação com a linguagem documentária (Borba, 2003): Observa-se, nos trechos de transcrições exemplificados abaixo, um processo acoplado ao conhecimento prévio do catalogador de assunto que o utiliza para tirar as conclusões ou determinar algum termo antecipadamente, sem uso da linguagem documentária do sistema:

- Aqui são sete documentos, então eu vou colocar Gestão educacional como sendo um assunto local por ele não estar autorizado. Eu atualizo o meu, Gestão educacional. (Catalogador A)

- Um outro é Gestão educacional que o BIBLIODATA também já reconhece, quer dizer ele não dá como autorizado, mas muita gente usa no 650 , então usa indevidamente. (Cataloga$\operatorname{dor}$ A)

- Organização escolar é um assunto não autorizado pelo BIBLIODATA, eu vou ter que passar para um assunto local. (Catalogador B)

- Então nesse caso aqui olha, esse "Cadeias de fornecimento" a gente I. Acha, é, importante porque ele fala, são cadeias mesmo de fornecimento, então a gente procura pôr. Então o quê que eu faço? Eu ponho no 690 que é o campo local. (Catalogador C) 


\begin{tabular}{|c|c|c|}
\hline Primeiro Catalogador - Biblioteca $A$ & Segundo Catalogador - Biblioteca B & Terceiro Catalogador - Biblioteca C \\
\hline $\begin{array}{l}\text { 1.Preenche o campo } 001 . \\
\text { 2.Preenche o campo } 08 \text {. } \\
\text { 3. Preenche os campos data, local de } \\
\text { publicação. } \\
\text { 4. Preenche o ISBN. } \\
\text { 5. Não utiliza os campos } 40 \text { e } 41 \text {. } \\
\text { 6. Diz sobre o assunto do documento. } \\
\text { 7. Olha o título, e que também observa a } \\
\text { catalogação na fonte. } \\
\text { 8.Faz a conferência do número de } \\
\text { classificação. } \\
\text { 9.Utiliza o campo de assunto local } \\
\text { 10.Procura entrada com organizadores e } \\
\text { autores. }\end{array}$ & $\begin{array}{l}\text { 1. Observa na UEP, no BIBLIODATA e } \\
\text { na LC o livro a ser catalogado. } \\
\text { 2. Preenche o campo 008, depois o } \\
\text { idioma e o ISBN. } \\
\text { 3. Coloca o autor e o título para ficar mais } \\
\text { fácil. } \\
\text { 4. Questiona sobre o uso da ficha } \\
\text { catalográfica. } \\
\text { 5. Diz que entrará pelo título. } \\
\text { 6. Preenche o campo } 260 \text {, que é o } \\
\text { campo da imprenta. } \\
\text { 7. O campo } 300 \text { da descrição física. } \\
\text { 8. Vai para o campo assunto, e já sabia } \\
\text { qual era o assunto. } \\
\text { 9. Entra no BIBLIODATA para procurar } \\
\text { se ele autoriza. } \\
\text { 10. Diz que o BIBLIODATA não autoriza } \\
\text { os termos, mas que outras pessoas } \\
\text { usaram no } 650 \text {. }\end{array}$ & $\begin{array}{l}\text { 1. Procura na base pelo título da obra. } \\
\text { 2. Preenche o campo } 001 \text {. } \\
\text { 3. O campo } 08 \text {, fala da data e do local de } \\
\text { publicação. } \\
\text { 4. Coloca o número do ISBN, coloca o } \\
\text { idioma. } \\
\text { 5. Descarta o campo da área geográfica. } \\
\text { 6. Faz a classificação do livro, dizendo } \\
\text { que se apóia além do CDD na tabela } \\
\text { Black que é específica em odontologia. } \\
\text { 7. Coloca o primeiro autor no campo } 245 \text {. } \\
\text { 8. Fala como procederia no caso de mais } \\
\text { autores, de colaboradores, de } \\
\text { organizadores e editores. } \\
\text { 9. Fala sobre a edição do livro, e como é } \\
\text { a primeira deixa em branco o local da } \\
\text { edição. } \\
\text { 10. Coloca a imprenta, se é ilustrado e a } \\
\text { série. }\end{array}$ \\
\hline
\end{tabular}

Quadro 1. Procedimentos realizados pelos três catalogadores durante a indexação.

Validação pela linguagem documentária (Borba, 2003): torna-se um procedimento errôneo se não for precedido da associação com a linguagem para compreensão do assunto. Nos trechos transcritos abaixo nota-se que os catalogadores estão condicionados a empregar a linguagem documentária, de forma que adotam o termo correspondente da linguagem documentária antes de obter a compreensão da tarefa executada:

- Então vamos ver se o BIBLIODATA.. Eu entro no BIBLIODATA para ver o que ele autoriza, porque no meu catálogo, naquela coisinha provisória lá, mas eu não tenho nenhuma informação disso, vai ter um momento que agora eu vou atualizar para que depois eu não precise recorrer ao BIBLIODATA uma outra vez. Então eu vou entrar pela Internet. Quando eu estou com muita pressa com o usuário aqui eu entro no $C D$, se o $C D$ contempla. $O$ $C D$ é mais rápido.(Catalogador $A$ )

- É, a gente procura reunir todos perto lá, mas aí, depois a gente, é, como o BIBLIODATA não aceita, não autoriza se vier cadeias de fornecimento, aí eu vou colocar /. ((O/P)) Você está entrando no BIBLIODATA? ((S1)) Eu vou procurar. (Catalogador $B$ )

- Então mas, aí tem um assunto, por exemplo, "Terceiro molar inferior" é um assunto importante. Você viu que ele está até no título "Molar impactado", está vendo. Então Molar impactado ele não tem, mas molar é um assunto importante. Só por molar, "Molares".(Catalogador C)

Dissociação ou não uso da linguagem documentária: os exemplos de trechos de transcri- ções mostram a tomada de decisões para identificar os termos sem uso da linguagem documentária:

- A classificação, para chegar a um assunto essa obra já tem que estar classificada. A classificação é o gargalo do processo, é a parte mais demorada. Eu tenho que ver que público que vai usar, quem vai ser o consumidor desse material, então a gente começa dando uma olhada. O título é sugestivo? Algumas vezes sim outras não, ele nunca é determinante ele pode ser sugestivo. (Catalogador A)

- E também a gente consulta os profissionais da área uma coisa mais da área para esclarecer os termos. É e quando é um termo mais específico, a gente vai atrás do profissional da área daí, por exemplo, tem aquela palavra então a gente pergunta "Professor, mas esse assunto pode pôr aqui dentro desse? Entendeu? Por exemplo, foi geração, "Posso pôr dentro de energia? Posso pôr dentro de elétrica?"a gente conversa com ele. (Catalogador B)

- A catalogação na fonte indica o quê? Tem catalogação que norteia bem, quando tem ótimo, a gente se orienta por ela e pelo resuminho que eu acho muito interessante da última capa, da quarta capa. (Catalogador $\mathrm{C}$ )

$\mathrm{Na}$ categoria de associação com a linguagem percebe-se a necessidade de uso de uma linguagem documentária auxiliar, pois a linguagem documentária não apresenta a especificidade desejada. A falta de especificidade da linguagem faz com que os catalogadores façam a associação com a linguagem utilizando o seu 
conhecimento prévio sobre o assunto, sem fazerem a validação do termo com a linguagem autorizada.

Durante a realização da catalogação de assunto, os catalogadores utilizaram-se da validação pela linguagem para determinar o assunto do documento, deixando transparecer a não compreensão da atividade realizada, pois estavam condicionados a empregar a linguagem documentária do sistema. Na validação pela linguagem, notou-se a necessidade de a linguagem documentária utilizada pela Rede Unesp ter especificidade.

$\mathrm{Na}$ terceira categoria os catalogadores consultaram outras fontes para identificar o assunto do documento, sem validação com a linguagem documentária: os profissionais especialistas das áreas de especialidade e a bibliotecária de referência que está em contato com os usuários locais e as necessidades reais desses usuários.

\section{Considerações finais}

Os catalogadores de assunto apresentaram dificuldades na representação documentária. Utilizaram o conhecimento prévio e linguagens documentárias em áreas específicas. Este aspecto nos leva a refletir sobre a importância da sistematização do tratamento temático em Bibliotecas Universitárias através de alguns pontos tratados nas seções teóricas desta pesquisa: o uso de linguagem documentária adequada, o conhecimento do contexto da biblioteca, o conhecimento prévio do catalogador de assunto, a política de indexação, entre outros.

O Protocolo Verbal Individual nos permitiu a visibilidade da atividade dos catalogadores, seus procedimentos, conhecimento prévio da linguagem documentária em Bibliotecas Universitárias da Unesp.

Uma das dificuldades apontadas pelos catalogadores de assunto na análise de assunto são a identificação e a tradução dos conceitos em relação ao assunto do documento que pode, possivelmente, ser falta de conhecimento prévio do profissional indexador, ou falha na linguagem documentária.

Verificou-se a necessidade de especificidade na Linguagem Documentária, pois os catalogadores não têm, eventualmente, a necessidade de a consultarem ou a terem como parâmetro para a catalogação de assunto. Constatou-se que utilizam o conhecimento sobre a linguagem documentária para determinarem os termos e reclamam da não especificidade dos assuntos, utilizando o campo local 690 para identificarem os termos que julgam representarem o documento.

Assim, constatou-se que é necessária a atualização da Linguagem Documentária da Unesp, pois não está sendo viável para a catalogação de assuntos, o que dificulta, em um primeiro momento, a atuação do catalogador de assunto e, posteriormente, a busca por assunto pelos usuários.

\section{Referências}

Bernard, J. A. (1995). Análisis y representación del conocimiento: aportaciones de la psicología cognitiva. // Scire. Zaragoza. 1:1 (en./jun. 1995) 57-79.

Borba, E. A. (). Leitura para indexação: o uso da Linguagem Documentária como estratégia específica do leitor profissional. 2003. 65f. Trabalho de Conclusão de Curso (Graduação em Biblioteconomia)-Faculdade de Filosofia e Ciências, Universidade Estadual Paulista, Marília, 2003.

Cavalcanti, M. C. (1989). I-n-t-e-r-a-ç-ã-o leitor-texto: aspectos de interpretação pragmática. Campinas: UNICAMP, 1989. 271 p.

Chaumier, J. (1980). Travail et methodes du/de la documentaliste: connaissance du problème. Paris: ESF/Libraries Techniques. 1980. Ex-posé 3, Chap. 3: L`indexation, 4247.

Cintra, A. M. M. et al. (2002). Para entender as linguagens documentárias. 2. ed. rev. e atual. São Paulo: Editora Polis, 2002.

Dias, E. W.; Naves, M. M. L.; Moura, M. A. (2007). O usuário-pesquisador e a análise de assunto. // Perspectivas em Ciência da Informação. Belo Horizonte. 6:2 (jul./dez. 2001) 205-221. http://www.eci.ufmg.br/pcionline/viewar ticle.php?id=362\&layout=abstract (17 jul. 2007).

Dias, E.W. (2007). Análise de assunto: percepção do usuário quanto ao conteúdo de documentos. // Perspectivas em Ciência da Informação. Belo Horizonte. 9:2 (jul./dez. 2004) 146-157. http://www.eci.ufmg.br/pcionline /viewarticle.php?id=73\&layout=abstract (6 jun. 2007).

Fujita, M. S. L.; Nardi, M.I.A.; Santos, S. dos. (1989). A leitura em análise documentária. // Transinformação. Campinas. 10:3 (set/dez. 1998) 13-31.

Fujita, M. S. L. (2003). A identificação de conceitos no processo de análise de assunto para indexação. // Revista Digital de Biblioteconomia e Ciência da Informação. Campinas. 1:1, jul. 2003. http://bibli.fae.unicamp.br/rev bib/index.html (11 abr. 2006).

Fujita, M. S. L. (2004). A leitura documentária na perspectiva de suas variáveis: leitor - texto -contexto. // Datagramazero: Revista da Ciência da Informação. Rio de Janeiro. 5:4 (ago. 2004).

Fujita, M. S. L.; Cervantes, B. M. N. (2005). Abordagem cognitiva do protocolo verbal na confirmação de termos para a construção de linguagem documentaria em inteligência competitiva. // Valentim, M.L.P. (Org). Métodos qualitativos de pesquisa em Ciência da Informação. São Paulo: Polis, 2005

Fujita, M. S. L. (2006). Política de tratamento da informação documentária da rede de bibliotecas da UNESP. Marília: FFC/UNESP, 2006.

Fujita, M. S. L. (2007). O contexto da leitura documentária de indexadores de bibliotecas universitárias em perspectiva sociocognitiva para a investigação de estratégias de ensino. 2007. 36 f. Descrição detalhada (Projeto 
Integrado de Pesquisa) - Faculdade de Filosofia e Ciências, Universidade Estadual Paulista; CNPq, Marília.

Koch, I. G. V. (2002). Desvendando os segredos do texto. São Paulo: Cortez, 2002. 168 p

Langridge, D. (1989). Subject analysis. London: BowkerSaur, 1989.

Lara, M. L. G. (2004). Linguagem documentária e terminologia. Transinformação, Campinas. 16:3 (set/dez. 2004) 231-240.

Larson, R. R. (1991). The decline of subject sear-ching: long term trends and patterns of index use in an online catalog. // Journal of the American Society for Information Science, Was-hington. 42:3 (abr. 1991) 197-215.

Kern-Semirenko, C. (1983). OPAC user logs: implications for bibliographic instruction. Li-brary $\mathrm{Hi}$ Tech. 1:3 (Winter, 1983) 27-35.

Naves, M. M. L. (2001). Estudo de fatores interferentes no processo de análise de assunto. // Perspectivas em Ciência da Informação, Belo Horizonte. 6:2 (jul./dez. 2001) 189-203. http://www.eci.ufmg.br/pcionline/viewar ticle.php?id=361layout=abstract (18 jun. 2007).

Novellino, M. S. F. (1996). Instrumentos e metodologias de representação da informação. Informação \& Informação, Londrina. 1:2 (jul./dez. 1996) 37-45.

Peters, T. A. (1989). When smart people fail: an analysis of the transaction log of an online public access catalog. // Journal of Academic Librarianship. 15:5 (1989) 267-273.

Pinto, B. V. (2001). Indexação documentária: uma forma de representação do conhecimento registrado. // Perspectivas em Ciência da Informação, Belo Horizonte. 6:2 (jul./dez. 2001) 223-234. http://www.eci.ufmg.br/pcionli ne/viewarticle.php?id=363\&layout=abstract $\quad$ (03 mai. 2007).

Santos, I. S. (1997). Avaliação de linguagem documentária para biblioteca escolar. 1997. $90 \mathrm{f}$. Trabalho de Conclusão de Curso (Graduação em Biblioteconomia)Faculdade de Filosofia e Ciências, Universidade Estadual Paulista, Marília. 1997.

Silva, M. dos R. da; Fujita, M.S.L. (2004). A prática de indexação: análise da evolução de tendências teóricas e metodológicas. // Transinformação. Campinas. 16:2 (maio/ago. 2004) 133-161.

Taylor, A. G. (1995). On the subject of subjects. // Journal of Academic Librarianship. 21 (nov. 1995) 484-491.

Fujita, Mariângela Spotti Lopes; Redigolo, Franciele Marques. O uso de linguagens documentárias por indexadores em contexto de bibliotecas universitárias: uma abordagem sociocognitiva com protocolo verbal. // Ibersid (2009) 125-132. ISSN 1888-0967. 